\title{
Pragmatic Language and School Related Linguistic Abilities in Siblings of Children with Autism
}

\author{
Noa Ben-Yizhak $\cdot$ Nurit Yirmiya $\cdot$ Ifat Seidman • \\ Raaya Alon · Catherine Lord · Marian Sigman
}

Published online: 16 September 2010

(C) The Author(s) 2010. This article is published with open access at Springerlink.com

\begin{abstract}
Siblings of probands with autism spectrum disorders are at higher risk for developing the broad autism phenotype (BAP). We compared the linguistic abilities (i.e., pragmatic language, school achievements, and underling reading processes) of 35 school-age siblings of children with autism (SIBS-A) to those of 42 siblings of children with typical development. Results indicated lower pragmatic abilities in a subgroup of SIBS-A identified with BAP related difficulties (SIBS-A-BAP) whereas school achievements and reading processes were intact. Furthermore, among SIBS-A-BAP, significant negative correlations emerged between the severity scores on the Autism Diagnostic Observation Schedule and full and verbal IQ scores. These results are discussed in the context of the developmental trajectories of SIBS-A and in relation to the BAP.
\end{abstract}

Keywords Autism - Siblings - Broad autism phenotype Language $\cdot$ Pragmatics $\cdot$ Learning difficulties

N. Ben-Yizhak $\cdot$ N. Yirmiya $(\bowtie) \cdot$ I. Seidman

Department of Psychology, Hebrew University of Jerusalem,

Mount Scopus, 91905 Jerusalem, Israel

e-mail: NYirmiya@gmail.com

R. Alon

School of Education, Hebrew University of Jerusalem,

Mount Scopus, 91905 Jerusalem, Israel

C. Lord

University of Michigan Autism and Communication Disorders Center, Ann Arbor, MI, USA

M. Sigman

Departments of Psychiatry and Psychology, University of California Los Angeles, Los Angeles, CA, USA

\section{Introduction}

It has long been known that autism spectrum disorders (ASD) have a strong genetic component, and that relatives of probands with ASD are at higher risk for the disorder. The risk for any form of ASD in siblings of probands with autism is 2-8\% (Muhle et al. 2004; Szatmari et al. 1998), much higher than the current $0.6 \%$ base rate for the general population (Levy et al. 2009). Researchers report an increased risk for siblings of probands with ASD to develop the more subtle form of ASD characteristics, referred to as the "broad autism phenotype" (e.g., Bolton et al. 1994; Pickles et al. 2000; Virkud et al. 2008). More specific characteristics beyond those comprising the triad of communication, social and behavioral impairments such as executive dysfunctions (Delorme et al. 2007; Happé et al. 2001; Pilowsky et al. 2007; Wong et al. 2006), externalizing and internalizing behavior problems (Fisman et al. 1996; Gold 1993), learning disabilities (Plumet et al. 1995), theory of mind abilities (Shaked et al. 2006), general cognitive abilities (Folstein et al. 1999; Fombonne et al. 1997; Pilowsky et al. 2007), and a range of linguistic features (Chuthapisith et al. 2007; Folstein et al. 1999; Le Couteur et al. 1996; Pilowsky et al. 2003; Smalley and Asarnow 1990) were proposed as additional possible components of the broad autism phenotype (BAP).

Given the high risk of siblings of probands with ASD (SIBS-A) to receive a diagnosis of ASD or to develop BAP-related difficulties, we conducted a longitudinal study in which we followed a sample of SIBS-A and siblings of children with typical development (SIBS-TD) from infancy to childhood. The main aims of the original study were to identify early markers of the risk for developing ASD or the BAP and to delineate the developmental trajectories of the siblings from birth into childhood (4 months to 
7 years). The aim of the present study was to re-evaluate the sample at the preadolescence stage-age of 9-12 years.

During their first 24 months of life, 28\% (11/39) of the SIBS-A in our sample were identified as having cognitive and/or language delays according to standardized assessments. Examination of the developmental trajectories of those SIBS-A identified with delays revealed that most of the difficulties observed up to age 36 months disappeared at 54 months, with the exception of continued lower language scores for some of the SIBS-A (Gamliel et al. 2007; Yirmiya et al. 2006; Yirmiya et al. 2007). At age 7 years, $40 \%(15 / 37)$ of the SIBS-A group were identified as having cognitive, language and/or school-related difficulties according to standardized assessments and parental reports. Examination of developmental trajectories from age 14 months to age 7 years revealed that for some of the SIBS-A, the difficulties were continuous and appeared throughout the years, whereas for other SIBS-A the difficulties were transient-present only at some stages of the study, and still for others, BAP-related difficulties appeared for the first time at age 7 years (Gamliel et al. 2009).

In our recent report regarding SIBS-A aged 9-12 years (Seidman et al., in press), after removing the 2 children diagnosed with ASD, 39\% of the SIBS-A (13/33) were identified with BAP-related difficulties (SIBS-A-BAP). In the current report, we set out to examine pragmatics, a linguistic skill that is severely impaired in individuals with ASD, as well as other specific linguistic aspects relevant to school-age children: school achievements (i.e., reading, spelling, and arithmetic skills) and underlying reading processes (i.e., decoding processes, orthographic knowledge, phonological awareness, short term phonological memory, and auditory discrimination).

Pragmatic impairments are universal in autism and comprise a significant element of the disorder; therefore, pragmatic difficulties are considered a natural candidate for the BAP. Pragmatics refers to the use of language in communication (Richards et al. 1985). It encompasses the organization of verbal discourse and the meaning derived from aspects of communication beyond the sentential level (Chapey 1994; Grice 1975; Paradis 1998; Prutting and Kirchner 1987). Whereas several researchers demonstrated pragmatic impairments in parents of probands with ASD (Folstein et al. 1999; Hurley et al. 2007; Landa et al. 1991, 1992; Piven et al. 1997; Whitehouse et al. 2007), the degree to which such impairments are evident in siblings remains unclear. Bishop et al. (2006) found that compared to typically developing children, significantly more SIBS-A scored more than two standard deviations below the mean on the Children's Communication Checklist-2 (CCC-2) total score, which includes pragmatic use of language as well as structural language skills. Yet, no group differences emerged for the CCC-2 index that was specific to pragmatic impairments. Folstein et al. (1999) and Pilowsky et al. (2003) did not find differences on the Pragmatic Rating Scale (PRS; Landa et al. 1992) scores between SIBS-A and comparison groups comprised of siblings of children with other developmental disorders.

Examining language abilities other than pragmatics, a growing body of research regarding infant and toddler SIBS-A supports language difficulties as a major component of the BAP in the preschool years (Elsabbagh and Johnson 2007; Landa and Garrett-Mayer 2006; Mitchell et al. 2006; Orsmond and Seltzer 2007; Toth et al. 2007; Yirmiya and Ozonoff 2007; Zwaigenbaum et al. 2005). Yet evidence for the manifestations of language difficulties among older SIBS-A is inconsistent. Some researchers found elevated rates of language impairments and specific learning disabilities in SIBS-A, as well as decreased achievements on a variety of language measures (Chuthapisith et al. 2007; Le Couteur et al. 1996; Plumet et al. 1995). For example, Plumet et al. (1995) found that siblings (aged 13-35 years) of female probands with autism achieved significantly lower scores than siblings of female probands with Down syndrome on measures of repetition, reading, spelling, vocabulary, phonological knowledge, and short-term verbal memory. Yet, others found no differences on language measures such as reading, spelling (Folstein et al. 1999; Freeman et al. 1989), phonological processing (Bishop et al. 2004), and receptive and expressive language (Pilowsky et al. 2003) between SIBS-A and different comparison groups or published norms. Moreover, SIBS-A scored higher on cognitive, language and reading abilities measures than siblings of children with specific language impairment (Lindgren et al. 2009).

Variability of previous findings regarding linguistic abilities among SIBS-A may be attributed at least in part, to methodological issues. These include age variability between and within samples of different studies (which constitutes a significant methodological issue as linguistic abilities are developmental in nature); variability in the types of measures employed for assessing language abilities (e.g., measures of general language level, or assessments of specific language aspects); and the variability within the SIBS-A groups tested, which included children who exhibited BAP difficulties and children who did not. In the current study, the relative homogeneity of ages, the use of measures assessing both specific and general language abilities, and the potential reduction of variability within groups by dividing our SIBS-A group into SIBS-ABAP and SIBS-A-TD, were expected to enable a better depiction of the language profiles of SIBS-A. We hypothesized that indeed SIBS-A who are diagnosed with the BAP would show lower language-related abilities. 
Furthermore, whereas language abilities and severity of symptoms were not found to be associated among individuals with autism (Gotham et al. 2009) we were interested in examining whether the lower language abilities, if found, would or would not be associated with the severity of the BAP as measured by the Autism Diagnostic Observation Schedule (ADOS; Lord et al. 2002) among SIBS-A-BAP.

\section{Method \\ Participants}

\section{The SIBS-A Group}

The SIBS-A group comprised 35 siblings (11 girls, 24 boys) between the ages of 9-12 years, having an older sibling with autism. The participants took part in our longitudinal study on the development of SIBS-A and were previously seen at the ages of $4,14,24,36$, and 54 months, and at 7 years. The SIBS-TD group comprised 42 siblings ( 21 girls, 21 boys) between the ages of $9-12$ years, having an older sibling with typical development.

The families were recruited through treatment centers in Israel, special schools, the Israeli national organization for children with autism, and families of children with autism. Thirty-two probands participated ( 7 girls/25 boys). Their diagnosis of autism was confirmed by two independent clinicians using the Autism Diagnostic Observation Schedule-Generic (ADOS-G; Lord et al. 2000) and/or the Autism Diagnostic Interview-Revised (ADI-R; Lord et al. 1994). Some of the probands were recruited before the availability of the ADOS-G in Israel and therefore were administered only the ADI-R. Parents were interviewed using the ADI-R and the Vineland Adaptive Behavior Scale-Interview Edition (VABS; Sparrow et al. 1985) regarding the proband with autism. The probands' IQ was measured with a standard IQ test appropriate to age and/or developmental ability. Based on these tests, 8 of the 32 probands were classified as high functioning (IQ and/or daily living skills score $>70$ ), whereas the remaining 24 probands were classified as low functioning (IQ and daily living skills score $\leq 70$ ).

Inclusion criteria for families in the SIBS-A group were: (a) intact families who had a child with autism and a younger sibling; (b) normal pregnancy with the participating sibling as reported by the parents, with no peri-, pre, or post-natal difficulties as well as normal gestational age ( $>36$ weeks); and (c) no medical conditions associated with autism such as Fragile $\mathrm{X}$ or tuberous sclerosis in the proband.
The SIBS-TD Group and Matching Procedure

The comparison group comprised 42 siblings (21 girls/21 boys) of typically developing children. Families in this SIBS-TD group were recruited from maternity wards in Jerusalem. Inclusion criteria required that: (a) the families were intact at the time of the study's initiation; (b) the older child exhibited typical development with no history of any medical, learning, and/or emotional difficulties and had not received any specialized interventions such as occupational therapy, speech and language therapy, or psychotherapy based on parental report; and (c) the pregnancy with the participating sibling was normal as reported by the parents.

The two groups were all Hebrew speaking Israelis. They were matched at age 4 months on a one-to one basis according to chronological age, sex, birth order, number of children in the family, sex of the older proband, temperament profile and Bayley (1993) mental and motor scores. SIBS-A who joined the study after the age of 4 months were matched to SIBS-TD according to the same variables, as closely as possible. Parents' age, ethnicity, income, and education level did not significantly differ between the two groups at the age of 4 months. At each age, we reexamined these background variables and found no significant differences between the groups.

Attrition rate at the current time point of 9-12 years was very low: Only three siblings from the 7-year SIBS-A group were not tested because one family relocated outside of Israel, one was unwilling to participate, and one could not be located.

\section{The Identification of Children with BAP-Related Difficulties (SIBS-A-BAP)}

We used the Baby Siblings Research Consortium (BSRC) diagnostic criteria presented in Table 1. The BSRC comprise several research groups who focuses on investigations of infants at risk for ASD and who participate in collaborative research activities and data sharing. Based on these criteria, the SIBS-A group was further classified into two subgroups: SIBS-A-BAP and SIBS-A-TD. The SIBS-ABAP subgroup comprised 13 SIBS-A ( 3 girls, 10 boys) who were identified with the BAP; that is, they showed an algorithm score of $\geq 4$ on the ADOS (Lord et al. 2002) and did not meet criteria for language delay, general developmental delay, ASD, or autistic disorder. The SIBS-A-TD subgroup comprised 19 SIBS-A (8 girls, 11 boys) who were typically developing; that is, none of their scores was lower than 2 standard deviations below the mean with possibly only one score falling 1.5 standard deviations below the mean; and they did not meet criteria for BAP, language delay, general developmental delay, ASD, or 
Table 1 Diagnostic outcome categories for siblings of children with autism (SIBS-A) and siblings of children with typical development (SIBS-TD)

\begin{tabular}{|c|c|c|c|}
\hline Diagnostic category & $\begin{array}{l}\text { SIBS-A } \\
(n=35)\end{array}$ & $\begin{array}{l}\text { SIBS-TD } \\
(n=42)\end{array}$ & Criteria \\
\hline Autism & $n=1$ & $n=0$ & $\begin{array}{l}\text { Above Autism cutoff on ADOS (Module } 3 \text { algorithm); and } \\
\text { Above Autism cutoff on SCQ; and } \\
\text { Meets DSM-IV criteria for autistic disorder }\end{array}$ \\
\hline Autism spectrum disorders (ASD) & $n=1$ & $n=0$ & $\begin{array}{l}\text { Above ASD cutoff on ADOS (Module } 3 \text { algorithm); and } \\
\text { Above ASD cutoff on SCQ; and } \\
\text { Meets DSM-IV criteria for PDD-NOS; and } \\
\text { Does not meet criteria for Autism }\end{array}$ \\
\hline General developmental delay (GDD) & $n=1$ & $n=0$ & $\begin{array}{l}\text { WISC Full IQ } \leq 78 \text {; and } \\
\text { At least one WISC performance subtest } \leq 5 \text {; and } \\
\text { CELF receptive or CELF expressive } \leq 78 \text {; and } \\
\text { Does not meet criteria for ASD or Autism }\end{array}$ \\
\hline Language delay (LD) & $n=0$ & $n=0$ & $\begin{array}{l}\text { CELF receptive or CELF expressive } \leq 70 \text {; or CELF receptive } \\
\text { and CELF expressive } \leq 78 \text {; and } \\
\text { Does not meet criteria for GDD, ASD, or Autism }\end{array}$ \\
\hline BAP difficulties & $n=13$ & $n=3$ & $\begin{array}{l}\text { ADOS score (Module } 3 \text { algorithm) } \geq 4 \text {; and } \\
\text { Does not meet criteria for LD, GDD, ASD, or Autism }\end{array}$ \\
\hline Typical development (TD) & $n=19$ & $n=38$ & $\begin{array}{l}\text { WISC Full IQ, Verbal IQ, and Performance IQ, and CELF } \\
\text { receptive and CELF expressive }>70 \text {; and } \\
\text { No more than one score } \leq 78 \text { on the WISC Full IQ, Verbal IQ, } \\
\text { Performance IQ, CELF receptive, or CELF expressive; and } \\
\text { Does not meet criteria for BAP Difficulties, LD, GDD, ASD, or Autism }\end{array}$ \\
\hline Other & $n=0$ & $n=1$ & Does not meet criteria for any of the above classifications \\
\hline
\end{tabular}

autism. As can be seen in Table 1, one of the SIBS-A was diagnosed with autistic disorder, one with ASD, and one with General developmental delay. These children were excluded from further analyses.

Among the SIBS-TD group (see Table 1) four children met clinical criteria, 3 for the BAP category and one for the "other" category and therefore were removed from further analyses. The remaining 38 children of the SIBS-TD group comprised the SIBS-TD-TD group (19 girls, 19 boys). No significant age and sex differences emerged among the three groups of SIBS-A-BAP, SIBS-A-TD, and SBS-TDTD $(p>.01)$. Groups' characteristics are presented in Table 2.

\section{Measures}

All tests have been translated to Hebrew and are ordinarily used in clinical evaluations and research but have not been validated in Israel with the exception of the ADI-R and the ADOS. Given the lack of available validated tests and the group comparison design of the current study in which the same tests were administered to the children at the same ages, this was the best possible approach available.

\section{Autism Diagnostic Observation Schedule (ADOS; Lord} et al. 2002)

The ADOS, one of the gold-standard diagnostic systems for ASD, is a semi-structured, standardized observational assessment designed to assess behaviors related to autism or ASD, based on the DSM-IV (American Psychiatric Association 1994) and the ICD-10 (World Health Organization 1992) criteria for ASD. The ADOS consists of four modules designated for use according to chronological age, language, and cognitive abilities. In the current study, Module 4 was administered to all participants and scored using the Module 3 revised algorithm (Gotham et al. 2007) because no revised algorithm is available for Module 4 (all participants were within the appropriate age range, and all items required for the Module 3 revised algorithm were administered). The Module 3 revised algorithm enabled us to generate calibrated severity scores of autistic features that were calculated according to participants' revised algorithm scores and chronological ages (Gotham et al. 2009). In addition, we calculated semantic-pragmatic profile (SPP) scores (C. Lord, personal communication, May 7, 2009), by summing up a subset of ADOS items 
Table 2 Age, sex, IQ, and language characteristics for siblings of children with autism (SIBS-A) and siblings of children with typical development (SIBS-TD)

\begin{tabular}{|c|c|c|c|}
\hline & \multicolumn{2}{|l|}{ SIBS-A } & \multirow{2}{*}{$\begin{array}{l}\text { SIBS-TD } \\
\text { SIBS-TD-TD } \\
(n=38)\end{array}$} \\
\hline & $\begin{array}{l}\text { SIBS-A-BAP } \\
(n=13)\end{array}$ & $\begin{array}{l}\text { SIBS-A-TD } \\
(n=19)\end{array}$ & \\
\hline \multicolumn{4}{|c|}{ Age in months } \\
\hline$M$ & 118.77 & 122.11 & 117.71 \\
\hline SD & 7.76 & 9.9 & 9.88 \\
\hline Range & $107-133$ & $107-145$ & $109-145$ \\
\hline Female:male & $3: 10$ & $8: 11$ & 19:19 \\
\hline \multicolumn{4}{|c|}{ Wechsler Intelligence Scale for Children (WISC): } \\
\hline \multicolumn{4}{|l|}{ Full IQ } \\
\hline$M$ & 110.54 & 106.58 & 104.30 \\
\hline SD & 13.40 & 10.92 & 9.87 \\
\hline \multicolumn{4}{|l|}{ Verbal IQ } \\
\hline$M$ & 115.46 & 109.95 & 106.32 \\
\hline SD & 15.13 & 13.38 & 11.00 \\
\hline \multicolumn{4}{|c|}{ Performance IQ } \\
\hline$M$ & 102.69 & 101.42 & 101.41 \\
\hline SD & 3.47 & 9.33 & 10.47 \\
\hline \multicolumn{4}{|c|}{ Clinical Evaluation of Language Fundamentals (CELF): } \\
\hline \multicolumn{4}{|c|}{ Total language score } \\
\hline$M$ & 113.33 & 111.16 & 107.95 \\
\hline SD & 12.99 & 12.20 & 10.60 \\
\hline \multicolumn{4}{|c|}{ Receptive language score } \\
\hline$M$ & 117.75 & 115.37 & 112.29 \\
\hline SD & 14.29 & 14.91 & 13.45 \\
\hline \multicolumn{4}{|c|}{ Expressive language score } \\
\hline$M$ & 108.5 & 106.32 & 103.53 \\
\hline SD & 11.91 & 11.28 & 10.53 \\
\hline
\end{tabular}

pertaining to semantic-pragmatic language impairments. Items comprising the SPP are presented in Table 3.

Because the study was carried out in participants' homes, it was impossible at times to conceal the group identity of the participant (e.g., the older sibling with autism was sometimes at home). Therefore, the ADOS administration was videotaped and later coded by 2 of 3 coders, blind to group membership and all other test procedures and data. Inter-rater reliability was assessed for 60 of the 70 administrations and yielded $91.47 \%$ agreement among the 3 coders with a kappa coefficient of .77 for all items (not only items comprising the algorithm).

\section{Severity Scores}

Severity scores of autistic features were calculated according to participants' ADOS algorithm score and chronological age (for full criteria, see Gotham et al. 2009). The distributions of severity scores among the SIBS-A-
BAP, SIBS-A-TD, and SIBS-TD-TD groups are presented in Fig. 1. As can be seen in Fig. 1, one sibling had a severity score of 9 which was an outlier compared to the rest of the severity scores which ranged from 1 to 6 and was therefore omitted from analyses.

\section{Social and Communication Questionnaire (SCQ; Rutter} et al. 2003)

The SCQ was used for siblings' assignment into diagnostic outcome categories. The SCQ, designed as a screening instrument for children aged 3 years and above to evaluate autism spectrum symptoms, has a cutoff score that can be used to indicate the likelihood that the child has ASD. The SCQ, a 40-item scale based on items from the ADI-R (Lord et al. 1994), offers two algorithms: a lifetime diagnosis, which refers to behavior throughout the child's lifetime, and a current algorithm, which focuses on the most recent 3-month period. The current version addressing the most recent 3-months was administered to the parents.

\section{Wide Range Achievement Tests (WRAT-III; Jastak and Wilkinson 1993)}

The WRAT-III assesses acquired school-related abilities. Examinees are required to read isolated words, spell dictated words, and solve arithmetic problems. Scaled scores for reading, spelling, and arithmetic are determined according to the corresponding chronological age. All three domains have a mean score of 100 and a standard deviation of 15 .

\section{Diagnostic Battery for Reading Processes in Hebrew} (NITZAN; Shalem and Lachman 1998)

This standardized diagnostic assessment is designed to assess reading-related learning disabilities in the Hebrew language. It consists of several subtests, evaluating decoding abilities (nonword reading, lists 1 and 2), orthographic knowledge (recognition of correct spelling patterns), phonological awareness (syllable omission, phoneme omission, word inversion), short-term phonological memory, and auditory discrimination of words. Raw scores are summed for each subtest, and a percentile score is generated according to the child's grade.

\section{Wechsler Intelligence Scale for Children (WISC-III;} Wechsler 1991)

The WISC-III is a standardized test designed to assess intellectual abilities of children between the ages of 6-16 years. Subtest scores are combined to provide scaled scores for verbal IQ, performance IQ, and full scale IQ. 
Table 3 Autism diagnostic observation schedule (ADOS): items comprising the semanticpragmatic profile (SPP)

\begin{tabular}{|c|c|c|}
\hline SPP items & $\begin{array}{l}\text { Included in the ADOS } \\
\text { algorithm }\end{array}$ & $\begin{array}{l}\text { Not included in } \\
\text { the ADOS algorithm }\end{array}$ \\
\hline \multicolumn{3}{|l|}{ Communication } \\
\hline Offers information (A5) & & $\checkmark$ \\
\hline Reports events (A7) & $\boldsymbol{V}$ & \\
\hline Asks for information (A6) & & $\checkmark$ \\
\hline Quality of social overtures (B9) & $\boldsymbol{v}$ & \\
\hline \multicolumn{3}{|l|}{ Orientation to speaker } \\
\hline Conversation (A8) & $\boldsymbol{v}$ & \\
\hline Amount of reciprocal social communication (B11) & $\boldsymbol{v}$ & \\
\hline Overall quality of rapport (B12) & $\boldsymbol{V}$ & \\
\hline Shared enjoyment in interaction (B4) & $\boldsymbol{v}$ & \\
\hline Empathy (comments on emotions of others) (B6) & & $\checkmark$ \\
\hline Preoccupations with specific interests (D4) & $\boldsymbol{v}$ & \\
\hline \multicolumn{3}{|l|}{ Semantic aspect (communication of information) } \\
\hline Stereotypical, repetitive, idiosyncratic language (A4) & $\boldsymbol{v}$ & \\
\hline Echolalia (A3) & & $\checkmark$ \\
\hline Overall level of non-echoed language (A1) & & $\checkmark$ \\
\hline Use of communicative gestures (A9) & $\boldsymbol{v}$ & \\
\hline $\begin{array}{l}\text { Language production and linked non-verbal } \\
\text { communication (B3) }\end{array}$ & & $\checkmark$ \\
\hline \multicolumn{3}{|l|}{ Play } \\
\hline Creativity $(\mathrm{C} 1)$ & & $\checkmark$ \\
\hline \multicolumn{3}{|l|}{ Speech abnormalities } \\
\hline Speech abnormalities associated with autism (A2) & & $\checkmark$ \\
\hline
\end{tabular}

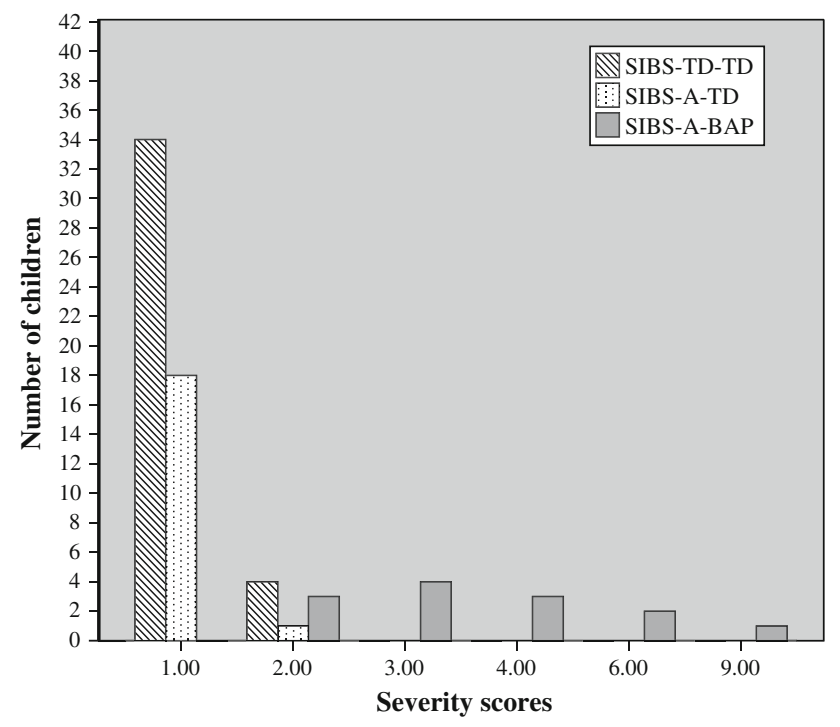

Fig. 1 Distribution of scores for severity of autistic features among siblings of children with autism (SIBS-A) and siblings of children with typical development (SIBS-TD)

\section{Clinical Evaluation of Language Fundamentals: 3rd Edition (CELF-III; Semel et al. 1995)}

The CELF-III is a standardized test designed to assess a wide range of language abilities of individuals between the ages of 6 and 21 years. Its subtest scores are summed into two scales, receptive language ability and expressive language ability, and combined into a total language score. All have a mean score of 100 and a standard deviation of 15 .

\section{Demographic Information}

Background details including the number of children, family income, parents' employment status, and parents' education were collected.

Procedure

Families were recontacted and reinvited to participate in the study. Each sibling was seen individually at home for three videotaped sessions. The WISC-III, the CELF-III, the NITZAN, and the WRAT-III were administered by the same experimenter during the first two sessions, each lasting about $120 \mathrm{~min}$. In the third session, which lasted about $60 \mathrm{~min}$, the ADOS was administered by a different experimenter. Each experimenter was blind to participants' performance on the other measures, and the first two sessions were randomly assigned. Parents completed the demographic questionnaires and the SCQ. Evaluation procedures were compatible with children's attention span and activity level. Breaks were given as often as needed. 
Parents received a detailed report summarizing their child's performance upon completion.

\section{Results}

Intergroup Analyses: Pragmatic Language, School Achievements, and Reading Processes

Analyses of variance were employed to compare the SPP, reading processes, and achievement scores of the three groups: SIBS-A-BAP ( $n=13)$, SIBS-A-TD $(n=19)$, and SIBS-TD-TD $(n=38)$.

\section{Pragmatic Language (SPP)}

Some of the items comprising the SPP are part of the ADOS algorithm with which an identification of the BAP was made. Therefore, we calculated and compared scores on two SPP subscales: one comprising SPP items that are included in the ADOS algorithm, and another comprising SPP items that are not included in the ADOS algorithm, and therefore are more independent of our classification system. Obviously, we expected to find group differences on the SPP items comprising the algorithm. Yet, we were interested in examining whether pragmatic impairments beyond those included in the ADOS algorithm would be also associated with differences among our three groups.

Analyses of variance among the three groups (SIBS-ABAP, SIBS-A-TD, and SIBS-TD-TD) was conducted using the non-parametric Kruskal-Wallis test. A significant difference emerged for the total score of the SPP items not comprising the ADOS algorithm $\left(\chi_{(2 / 70)}^{2}=5.99, p=.05\right)$, and as expected for the total score of SPP items comprising the ADOS algorithm $\left(\chi_{(2 / 70)}^{2}=28.68, p=.00\right)$. As a group SIBS-A-BAP received a significantly higher score (poorer performance) than the SIBS-A-TD and SIBS-TD-TD groups on the total SPP score of the items not comprising the ADOS algorithm and as expected, this group also received a significantly higher score on the total SPP items comprising the ADOS algorithm (see Table 4).

Interestingly, the 3 children (two boys and one girl) from the SIBS-TD group who were identified with BAP had similar SPP scores to those of the SIBS-A-BAP (i.e., higher score indicating poorer pragmatic performance). However, their cognitive and linguistic scores were
Table 4 Semantic-pragmatic profile (SPP) Scores for siblings of children with autism (SIBS-A) and siblings of children with typical development (SIBS-TD)

\begin{tabular}{|c|c|c|c|c|}
\hline \multirow[t]{2}{*}{ SPP subscale } & \multicolumn{2}{|l|}{ SIBS-A } & \multirow{2}{*}{$\begin{array}{l}\text { SIBS-TD } \\
\text { SIBS-TD-TD } \\
(n=38)\end{array}$} & \multirow[t]{2}{*}{ Kruskal-Wallis test } \\
\hline & $\begin{array}{l}\text { SIBS-A-BAP } \\
(n=13)\end{array}$ & $\begin{array}{l}\text { SIBS-A-TD } \\
(n=19)\end{array}$ & & \\
\hline \multicolumn{5}{|c|}{ ADOS algorithm items } \\
\hline$M$ & 4.46 & .63 & .68 & SIBS-A-BAP > SIBS-A-TD \\
\hline SD & 3.52 & 1.06 & .90 & $\begin{array}{l}\text { SIBS-A-BAP > SIBS-TD-TD } \\
\text { SIBS-A-TD = SIBS-TD-TD }\end{array}$ \\
\hline \multicolumn{5}{|c|}{ Non-algorithm items } \\
\hline$M$ & 3.92 & 1.52 & 1.94 & SIBS-A-BAP > SIBS-A-TD \\
\hline SD & 3.52 & 1.43 & 1.64 & $\begin{array}{l}\text { SIBS-A-BAP > SIBS-TD-TD } \\
\text { SIBS-A-TD = SIBS-TD-TD }\end{array}$ \\
\hline
\end{tabular}

\begin{tabular}{|c|c|c|c|}
\hline \multirow{2}{*}{$\begin{array}{l}\text { Wide range achievement } \\
\text { test (WRAT) }\end{array}$} & \multicolumn{2}{|l|}{ SIBS-A } & \multirow{2}{*}{$\begin{array}{l}\text { SIBS-TD } \\
\text { SIBS-TD-TD } \\
(n=38)\end{array}$} \\
\hline & $\begin{array}{l}\text { SIBS-A-BAP } \\
(n=13)\end{array}$ & $\begin{array}{l}\text { SIBS-A-TD } \\
(n=19)\end{array}$ & \\
\hline \multicolumn{4}{|l|}{ Reading } \\
\hline$M$ & 118.08 & 121.26 & 117.8 \\
\hline SD & 7.61 & 12.38 & 12.71 \\
\hline \multicolumn{4}{|l|}{ Spelling } \\
\hline$M$ & 126.31 & 122.8 & 116.34 \\
\hline SD & 14.5 & 22.83 & 19.62 \\
\hline \multicolumn{4}{|l|}{ Arithmetic } \\
\hline$M$ & 108.46 & 106.58 & 102.68 \\
\hline SD & 13.68 & 13.1 & 8.55 \\
\hline
\end{tabular}

Table 5 School achievement test scores (WRAT) for siblings of children with autism (SIBS-A) and siblings of children with typical development (SIBS-TD) 
Table 6 Reading processes test scores (NITZAN) for siblings of children with autism (SIBS-A) and siblings of children with typical development (SIBS-TD)

\begin{tabular}{|c|c|c|c|}
\hline \multirow[t]{2}{*}{ NITZAN } & \multicolumn{2}{|l|}{ SIBS-A } & \multirow{2}{*}{$\begin{array}{l}\text { SIBS-TD } \\
\text { SIBS-TD-TD } \\
(n=38)\end{array}$} \\
\hline & $\begin{array}{l}\text { SIBS-A-BAP } \\
(n=13)\end{array}$ & $\begin{array}{l}\text { SIBS-A-TD } \\
(n=19)\end{array}$ & \\
\hline \multicolumn{4}{|c|}{ Decoding processes for reading nonwords } \\
\hline \multicolumn{4}{|l|}{ List 1} \\
\hline$M$ & 57.86 & 63.55 & 56.07 \\
\hline SD & 30.44 & 28.81 & 27.88 \\
\hline \multicolumn{4}{|l|}{ List 2} \\
\hline$M$ & 52.78 & 64.74 & 53.8 \\
\hline SD & 29.04 & 29.91 & 24.83 \\
\hline \multicolumn{4}{|c|}{ Orthographic knowledge: spelling pattern recognition } \\
\hline$M$ & 84.2 & 71.66 & 64.55 \\
\hline SD & 27.61 & 33.66 & 36.37 \\
\hline \multicolumn{4}{|c|}{ Phonological awareness } \\
\hline \multicolumn{4}{|c|}{ Syllable omission } \\
\hline$M$ & 69.27 & 76.43 & 57.87 \\
\hline SD & 28.72 & 21.04 & 27.88 \\
\hline \multicolumn{4}{|c|}{ Phoneme omission } \\
\hline$M$ & 56.74 & 55.9 & 52.77 \\
\hline SD & 25.07 & 34.48 & 30.41 \\
\hline \multicolumn{4}{|c|}{ Word inversion } \\
\hline$M$ & 61.59 & 61.86 & 59.13 \\
\hline SD & 26.66 & 29.6 & 36.42 \\
\hline \multicolumn{4}{|c|}{ Short-term phonological memory } \\
\hline$M$ & 52.8 & 45.95 & 51.26 \\
\hline SD & 32.14 & 33.98 & 27.52 \\
\hline \multicolumn{4}{|c|}{ Auditory discrimination } \\
\hline$M$ & 16.07 & 22.44 & 27.82 \\
\hline SD & 11.22 & 21.25 & 25 \\
\hline
\end{tabular}

relatively low (mostly below 100) compared to the majority of the children in the SIBS-A-BAP group who mostly scored above 100 . This group of three children is too small for statistical analyses.

\section{School Achievements and Reading Processes}

Analyses of variance revealed no significant overall group effect for the WRAT reading, spelling, and arithmetic scores, $F_{(6,130)}=1.1, p=.36, \eta_{p}^{2}=.05$ (see Table 5). Similarly, analyses of variance revealed no significant overall group effect for the eight Hebrew-reading processes subtests of the NITZAN (nonword reading lists 1 and 2, spelling pattern recognition, syllable omission, phoneme omission, word inversion, short-term phonological memory, and auditory discrimination) among the three groups, $F_{(16,120)}=1.12, p=.34, \eta_{p}^{2}=.13$ (see Table 6$)$.
Intragroup Analyses

Pearson correlation coefficients were calculated for the SIBS-A-BAP group between ADOS severity scores and cognitive scores (i.e., verbal, performance and full IQ scores) and general linguistic abilities (receptive and expressive language scores). Significant negative correlations emerged between the ADOS severity score and the WISC full IQ score $(r=-.63, p=.03)$ and the verbal IQ score $(r=-.64, p=.03)$. No other significant correlations emerged for performance IQ or the CELF linguistic scores. These analyses could not be calculated for the groups of SIBS-A-TD and SIBS-TD-TD because per definition these participants had low severity scores and thus there was not enough variability in the ADOS severity scores.

We also examined possible associations between the probands' level of functioning (low vs. high functioning) and siblings' cognitive and linguistic functioning among the full sample of SIBS-A. No significant differences emerged for the cognitive scores (i.e., verbal, performance and full IQ scores), for the general linguistic abilities (CELF receptive and expressive language scores), and for the SPP scores between siblings who have an older brother or sister who is high-functioning and siblings who have an older brother or sister who is low-functioning (all $p$ 's $>.05)$ Thus, our findings indicate no evidence of familial liability regarding these abilities.

\section{Discussion}

Pragmatic language abilities, acquired school-related abilities, and reading processes of school-age SIBS-A and SIBS-TD were compared. Dividing our sample of SIBS-A into those identified with BAP (SIBS-A-BAP) and those identified with TD (SIBS-A-TD) enabled us to better illustrate the pattern of linguistic abilities that characterizes BAP in SIBS-A. SIBS-A-BAP showed poorer performance only on a measure of pragmatic language compared to SIBS-A-TD and SIBS-TD-TD, whereas no significant findings emerged for general linguistic measures as well as for school achievement and reading processes measures.

Taken together, these findings suggest that lowered pragmatic abilities, which constitute a universal impairment in ASD, also comprise the BAP in school-age SIBSA, whereas cognitive abilities, receptive and expressive language abilities, and other school-related abilities, as examined in the current study are intact. Furthermore, the performance of SIBS-A-TD indicates that this group is indeed developing typically, at least as measured in this study. 
The observation of lower pragmatic performance of SIBS-A-BAP in our sample coincides with Bishop et al. (2006) but contradicts Folstein et al. (1999) and Pilowsky et al. (2003), who reported no differences between SIBS-A and a control group on the PRS scores. Dividing our group of SIBS-A into SIBS-A-BAP and SIBS-A-TD subgroups enabled us to better detect the pragmatic impairments of some of these siblings. The use of a group of SIBS-A as a whole in other studies may have masked differences that existed in the pragmatic domain. Furthermore, the inconsistencies between research outcomes may result from the utilization of different measures. Although both the PRS and SPP ratings are based on an interaction of the examiner and the child, it is possible that the latter affords more opportunities to observe abnormal pragmatic behaviors because its coding system (the ADOS) requires approximately $45 \mathrm{~min}$ of interaction, whereas the PRS only requires a minimum of $15 \mathrm{~min}$.

Regarding language abilities, Kjelgaard and TagerFlusberg (2001) promoted the hypothesis regarding genetic and phenotypic overlap between specific language impairment (SLI) and autism by noting that poor nonword repetition which is considered as a psycholinguistic marker of SLI, is evidenced in children with autism who have borderline or low language abilities. Our findings that structural linguistic impairments do not comprise BAP manifestations in SIBS-A, and more specifically that SIBSA-BAP reveal similar performance to SIBS-TD-TD on the phonological processing measures, do not lend support to this hypothesis. The current findings replicate Bishop et al.'s (2004) report of a lack of differences in phonological processing measures among siblings and parents of children with autism. Along the same lines, Whitehouse, Barry, and Bishop (2008) suggest that structural language deficits, including poor nonword repetitions, do not reflect etiological overlap between SLI and autism but that they arise as a consequence of substantial impairments in multiple autistic domains. These researchers showed that although probands with autism with structural language difficulties presented nonword repetition difficulties, their pattern of errors on this test was different than that of children with SLI.

Furthermore, examination of the correlations between severity scores for autistic features and cognitive and linguistic measures in the SIBS-A-BAP subgroup suggested an interesting pattern: Whereas as a group SIBS-A-BAP showed better verbal IQ scores and similar full scale IQ scores to the other two groups (Seidman et al., in press), their performance on these measures was negatively correlated with the severity of their autistic features. In other words, lower verbal and full IQ scores were associated with a higher expression of autistic features in the SIBS-A-BAP subgroup. Gotham et al. (2009) found that the severity of scores in their sample of ASD participants was independent of participants' performance IQ scores and was relatively independent of participants' verbal IQ scores, whereas in their combined sample of nonspectrum participants (children with other disorders) and ASD participants, verbal IQ was a significant predictor of severity. Our findings add to this literature by revealing that among SIBS-A, severity of autistic symptoms is associated with Full scale and Verbal IQ scores. Finally, no associations were found between probands' level of functioning (low vs. high functioning) and siblings' cognitive and linguistic functioning, indicating no evidence of familial liability for these abilities in this ample.

Limitations of the current study include its small sample size, as well as the lack of other comparison groups. However, using a comparison group of typically developing children enabled us to conclude that the SIBS-A identified with TD truly show a picture similar to that of siblings of typically developing children in the domain of linguistic aspects, including pragmatics, which is significantly impaired in SIBS-A identified with BAP. The use of the ADOS score of SPP as a measure of pragmatic impairment comprises another limitation as it includes ADOS items, which served to identify BAP in our former report regarding 9-12 years (Seidman et al., in press). We solved this problem by showing that SIBS-A-BAP exhibit poorer pragmatic abilities not only on the SPP items comprising the ADOS algorithm with which BAP classification was made but also separately on the SPP items that did not comprise the ADOS algorithm. Nevertheless, further studies are required to replicate our findings.

Acknowledgments This study was supported by the United StatesIsrael Binational Science Foundation (BSF), Grant \# 2007209, awarded to NY, MS, and CL, and by grant no. 300000-4950 from the Public Committee for Allocation of Estate Funds, Ministry of Justice, Israel. We are grateful to the families who took part for their cooperation and to Dee B. Ankonina for her editorial assistance.

Open Access This article is distributed under the terms of the Creative Commons Attribution Noncommercial License which permits any noncommercial use, distribution, and reproduction in any medium, provided the original author(s) and source are credited.

\section{References}

American Psychiatric Association. (1994). Diagnostic and statistical manual of mental disorders-Text (4th ed.). Washington, DC: American Psychiatric Association.

Bayley, N. (1993). Bayley scales of infant development (2nd ed.). San Antonio, TX: Psychological Corporation.

Bishop, D. V. M., Maybery, M., Wong, D., Maley, A., \& Hallmayer, J. (2006). Characteristics of the broader phenotype in autism: A study of siblings using the children's communication checklist-2. 
American Journal of Medical Genetics: Part B. Neuropsychiatric Genetics, 128B, 54-60.

Bishop, D. V. M., Maybery, M., Wong, D., Maley, A., Hill, H., \& Hallmayer, J. (2004). Are phonological processing deficits part of the broad autism phenotype? American Journal of Medical Genetics: Part B. Neuropsychiatric Genetics, 141B, 117-122.

Bolton, P., Macdonald, H., Pickles, A., Rios, P., Goode, S., Crowson, M., et al. (1994). A case-control family history study of autism. Journal of Child Psychology and Psychiatry, 35, 877-900.

Chapey, R. (Ed.). (1994). Language intervention strategies in adult aphasia. Baltimore: Williams \& Wilkins.

Chuthapisith, J., Ruangdaraganon, N., Sombuntham, T., \& Roongpraiwan, R. (2007). Language development among the siblings of children with autistic spectrum disorder. Autism, 11, 149-160.

Delorme, R., Gouss, V., Roy, I., Trandafir, A., Mathieu, F., MourenSimoni, M., et al. (2007). Shared executive dysfunctions in unaffected relatives of patients with autism and obsessivecompulsive disorder. European Psychiatry, 22, 32-38.

Elsabbagh, M., \& Johnson, M. H. (2007). Infancy and autism: Progress, prospects, and challenges. Progress in Brain Research, 164, 355-383.

Fisman, S., Wolf, L., Ellison, D., Gillis, B., Freeman, T., \& Szatmari, P. (1996). Risk and protective factors affecting the adjustment of siblings of children with chronic disabilities. Journal of the American Academy of Child and Adolescent Psychiatry, 35, $1532-1541$.

Folstein, S. E., Santangelo, S. L., Gilman, S. E., Piven, J., Landa, R., Lainhart, J., et al. (1999). Predictors of cognitive test patterns in autism families. Journal of Child Psychology and Psychiatry, 40, $1117-1128$

Fombonne, E., Bolton, P., Prior, J., Jordan, H., \& Rutter, M. (1997). A family study of autism: Cognitive patterns and levels in parents and siblings. Journal of Child Psychology and Psychiatry, 38, 667-683.

Freeman, B. J., Ritvo, E. R., Mason-Brothers, A., Pingree, C., Yokota, A., Jenson, W., et al. (1989). Psychometric assessment of firstdegree relatives of 62 autistic probands in Utah. American Journal of Psychiatry, 146, 361-364.

Gamliel, I., Yirmiya, N., Jaffe, D., Manor, O., \& Sigman, M. (2009). Developmental trajectories in siblings of children with autism: Cognition and language from 4 months to 7 years. Journal of Autism and Developmental Disorders, 39, 1131-1144.

Gamliel, I., Yirmiya, N., \& Sigman, M. (2007). The development of young siblings of children with autism from 4 to 54 months. Journal of Autism and Developmental Disorders, 37, 171-183.

Gold, N. (1993). Depression and social adjustment in siblings of boys with autism. Journal of Autism and Developmental Disorders, 23, 147-163.

Gotham, K., Pickles, A., \& Lord, C. (2009). Standardizing ADOS scores for a measure of severity in autism spectrum disorders. Journal of Autism and Developmental Disorders, 39, 693-705.

Gotham, K., Risi, S., Pickles, A., \& Lord, C. (2007). The autism diagnostic observation schedule (ADOS): Revised algorithms for improved diagnostic validity. Journal of Autism and Developmental Disorders, 37, 400-408.

Grice, H. (1975). Logic and conversation. In P. Cole \& J. Morgan (Eds.), Syntax and semantics: Speech acts (Vol. 3, pp. 41-58). New York: Academic Press.

Happé, F., Briksman, J., \& Frith, U. (2001). Exploring the cognitive phenotype of autism: Weak "central coherence" in parents and siblings of children with autism. Vol. I. Experimental tests. Journal of Child Psychology and Psychiatry, 42, 299-307.

Hurley, R., Losh, M., Parlier, M., Reznick, J., \& Piven, J. (2007). The broad autism phenotype questionnaire. Journal of Autism and Developmental Disorders, 37, 1679-1690.

Jastak, S., \& Wilkinson, G. (1993). The wide range achievement test(WRAT-III) (3rd ed.). Wilmington: Jastak.
Kjelgaard, M. M., \& Tager-Flusberg, H. (2001). An investigation of language impairment in autism: Implications for genetic subgroups. Language and Cognitive Processes, 16, 287-308.

Landa, R., Folstein, S. E., \& Isaacs, C. (1991). Spontaneous narrativediscourse performance of parents of autistic individuals. Journal of Speech and Hearing Research, 34, 1339-1345.

Landa, R., \& Garrett-Mayer, B. (2006). Development in infants with autism spectrum disorders: A prospective study. Journal of Child Psychology and Psychiatry, 47, 629-638.

Landa, R., Piven, J., Wzorek, M. M., Gayle, J. O., Chase, G. A., \& Folstein, S. E. (1992). Social language use in parents of autistic individuals. Psychological Medicine, 22, 245-254.

Le Couteur, A., Bailey, A., Goode, S., Pickles, A., Robertson, S., Gottesman, I., et al. (1996). A broader phenotype of autism: The clinical spectrum in twins. Journal of Child Psychology and Child Psychiatry, 37, 785-801.

Levy, S. E., Mandell, D. S., \& Schultz, R. T. (2009). Autism. The Lancet, 374, 1627-1638.

Lindgren, K. A., Folstein, S. E., Tomblin, J. B., \& Tager-Flusberg, H. (2009). Language and reading abilities of children with autism spectrum disorders and specific language impairment and their first-degree relatives. Autism Research, 2, 22-38.

Lord, C., Risi, S., Lambrecht, L., Cook, E. H., Leventhal, B., DiLavore, P. C., et al. (2000). The autism diagnostic observation schedule-generic: A standard measure of social and communication deficits associated with the spectrum of autism. Journal of Autism and Developmental Disorders, 30, 205-223.

Lord, C., Rutter, M., DiLavore, P. C., \& Risi, S. (2002). Autism diagnostic observation schedule. Los Angeles: Western Psychological Services.

Lord, C., Rutter, M., \& Le Couteur, A. (1994). Autism diagnostic interview-revised: A revised version of a diagnostic interview for caregivers of individuals with possible pervasive developmental disorders. Journal of Autism and Developmental Disorders, 24, 659-685.

Mitchell, S., Brian, J., Zwaigenbaum, L., Roberts, W., Szatmari, P., Smith, I., et al. (2006). Early language and communication development of infants later diagnosed with autism spectrum disorder. Journal of Developmental and Behavioral Pediatrics, 27, S69-S78.

Muhle, R., Trentacoste, S. V., \& Rapin, I. (2004). The genetics of autism. Pediatrics, 113, e472-e486.

Orsmond, G. I., \& Seltzer, M. M. (2007). Siblings of individuals with autism spectrum disorders across the life course. Mental Retardation and Developmental Disabilities Research Review, 13, 313-320.

Paradis, M. (1998). The other side of language: Pragmatic competence. In M. Paradis (Ed.), Pragmatics in neurogenic communication disorders (pp. 1-10). Oxford, England: Elsevier.

Pickles, A., Starr, E., Kazak, S., Bolton, P., Papanikolaou, K., Bailey, A., et al. (2000). Variable expression of the autism broader phenotype: Findings from extended pedigrees. Journal of Child Psychology and Psychiatry, 41, 491-502.

Pilowsky, T., Yirmiya, N., Shalev, R., \& Gross-Tsur, V. (2003). Language abilities of siblings of children with autism. Journal of Child Psychology and Psychiatry, 44, 914-925.

Pilowsky, T., Yirmiya, N., Shalev, R., \& Gross-Tzur, V. (2007). Neuropsychological functioning of siblings of children with autism, siblings of children with developmental language delay, and siblings of children with mental retardation of unknown genetic etiology. Journal of Autism and Developmental Disorders, 37, 537-552.

Piven, J., Palmer, P., Landa, R., Santangelo, S., Jacobi, D., \& Childress, D. (1997). Personality and language characteristics in parents from multiple-incidence autism families. American Journal of Medical Genetics (Neuropsychiatric Genetics), 74, $398-411$. 
Plumet, M. H., Goldblum, M. C., \& Leboyer, M. (1995). Verbal skills in relatives of autistic females. Cortex, 31, 723-733.

Prutting, C., \& Kirchner, D. (1987). A clinical appraisal of the pragmatic aspects of language. Journal of Speech and Hearing Disorders, 52, 105-119.

Richards, J., Platt, J., \& Weber, H. (1985). Longman dictionary of applied linguistics. Harlow, England: Longman.

Rutter, M., Bailey, A., Lord, C., \& Berument, S. (2003). Social communication questionnaire (SCQ). Los Angeles: Western Psychological Services.

Seidman, I., Yirmiya, N., Alon, R., Ben Yitzhak, N., Lord, C., \& Sigman, M. (in press). Diagnostic outcomes in school-age siblings of children with autism. International Public Health Journal.

Semel, E., Wiig, E. H., \& Secord, W. A. (1995). Clinical evaluation and language fundamentals (CELF) (3rd ed.). San Antonio: Psychological Corporation/Harcourt Brace.

Shaked, M., Gamliel, I., \& Yirmiya, N. (2006). Theory of mind abilities in young siblings of children with autism. Autism, 10, 173-187.

Shalem, Z., \& Lachman, D. (1998). Diagnostic battery for reading processes in Hebrew. Tel Aviv: Nitzan Israeli Association for the Advancement of Children with Learning Disabilities.

Smalley, S. L., \& Asarnow, R. F. (1990). Brief report: Cognitive subclinical markers in autism. Journal of Autism and Developmental Disorders, 20, 271-278.

Sparrow, S. S., Balla, D. A., \& Cicchetti, D. V. (1985). Vineland adaptive behavior scales. Circle Pines, MN: American Guidance Services.

Szatmari, P., Jones, M., Zwaigenbaum, L., \& MacLean, J. (1998). Genetics of autism: Overview and new directions. Journal of Autism and Developmental Disorders, 28, 351-368.

Toth, K., Dawson, J., Meltzoff, A. N., Greenson, J., \& Fein, D. (2007). Early social, imitation, play, and language abilities of young non-autistic siblings of children with autism. Journal of Autism and Developmental Disorders, 37, 145-157.
Virkud, Y., Todd, R., Abbacchi, A., Zhang, Y., \& Constantino, J. (2008). Familial aggregation of quantitative autistic traits in multiplex versus simplex autism. American Journal of Medical Genetics: Part B. Neuropsychiatric Genetics, 150B, 328-334.

Wechsler, D. (1991). Wechsler intelligence scale for childrenWISCIII (3rd ed.). San Antonio: Psychological Corporation.

Whitehouse, A. J. O., Barry, J. G., \& Bishop, D. V. M. (2007). The broader language phenotype of autism: A comparison with specific language impairment. Journal of Child Psychology and Psychiatry, 48, 822-830.

Whitehouse, A. J. O., Barry, J., \& Bishop, D. V. M. (2008). Further defining the language impairment of autism: Is there a specific language impairment subtype. Journal of Communication Disorders, 41, 319-336.

Wong, D., Maybery, M., Bishop, D., Maley, A., \& Hallmayer, J. (2006). Profiles of executive function in parents and siblings of individuals with autism spectrum disorders. Genes, Brain and Behavior, 5, 561-576.

World Health Organization. (1992). The ICD-10 classification of mental and behavioural disorders: Clinical descriptions and diagnostic guidelines. Geneva: World Health Organization.

Yirmiya, N., Gamliel, I., Pilowsky, T., Baron-Cohen, S., Feldman, R., \& Sigman, M. (2006). The development of siblings of children with autism at 4 and 14 months: Social engagement, communication and cognition. Journal of Child Psychology and Psychiatry, 47, 511-523.

Yirmiya, N., Gamliel, I., Shaked, M., \& Sigman, M. (2007). Cognitive and verbal abilities in 24- and 36-month-old siblings of children with autism. Journal of Autism and Developmental Disorders, 37, 218-229.

Yirmiya, N., \& Ozonoff, S. (2007). The very early autism phenotype. Journal of Autism and Developmental Disorders, 37, 1-11.

Zwaigenbaum, L., Bryson, S., Rogers, T., Roberts, W., Brian, J., \& Szatmari, P. (2005). Behavioral manifestations of autism in the first year of life. International Journal of Developmental Neuroscience, 23, 143-152. 